University of Massachusetts Amherst

ScholarWorks@UMass Amherst

Chemistry Department Faculty Publication Series

Chemistry

1988

\title{
Flow-Injection Techniques for the Removal of Stable-Compound Interferences in Flame Atomic Absorption Spectrometry of Calcium
}

\author{
C. E. Adeeyinwo \\ Loughborough University of Technology \\ Julian Tyson \\ University of Massachusetts Amherst
}

Follow this and additional works at: https://scholarworks.umass.edu/chem_faculty_pubs

Part of the Chemistry Commons

\section{Recommended Citation}

Adeeyinwo, C. E. and Tyson, Julian, "Flow-Injection Techniques for the Removal of Stable-Compound Interferences in Flame Atomic Absorption Spectrometry of Calcium" (1988). Analytica Chimica Acta. 1395.

Retrieved from https://scholarworks.umass.edu/chem_faculty_pubs/1395 


\title{
FLOW-INJECTION TECHNIQUES FOR THE REMOVAL OF STABLE-COMPOUND INTERFERENCES IN FLAME ATOMIC ABSORPTION SPECTROMETRY OF CALCIUM
}

\author{
C.E. ADEEYINWO and J.F. TYSON* \\ Department of Chemistry, University of Technology, Loughborough, Leicestershire LE11 $3 T U$ \\ (Great Britain)
}

(Received 11th March 1988)

\section{SUMMARY}

The effects of phosphate and aluminium on calcium in an air/acetylene flame were studied in a flow-injection system. The depressive effect of phosphate was eliminated by operating the nebulizer under starvation conditions with air compensation. Pulse dampers were incorporated into the flow line and the instrument operating conditions were optimized for minimum interference. The depressive effect of aluminium could not be removed in this way. To achieve this, a two-line manifold was used in which the calcium was precipitated as oxalate, retained on a membrane filter and redissolved in hydrochloric acid. Up to $200 \mathrm{mg} \mathrm{l}^{-1}$ aluminium could be tolerated with a precision of $2 \%$ for $10 \mathrm{mg} \mathrm{l}^{-1}$ calcium.

The depressive effects of aluminium, phosphate, silicate, etc. in the determination of calcium in an air/acetylene flame are well documented [1-5]. These effects are classified as vapourisation interference in which the refractory compounds formed from the solution matrix on evaporation in the flame less readily yield gas-phase atoms. These interferences have traditionally been eliminated or controlled by one or more of the following methods: (1) suitable adjustment of instrument parameters such as burner height, flame fuel, and fuel/oxidant ratio $[5,6]$, but this often sacrifices sensitivity and has little effect on the severe depression caused by aluminium; (2) addition of a large excess of a releasing or protecting agent such as lanthanum or strontium ions or EDTA to the solutions, but the high solute concentration which results from such additions can produce burner clogging, and excess of lanthanum can cause aerosol ionic redistribution which in turn distorts the atom profile in the flame, thereby causing errors [7]; and (3) isolation of the calcium from the interferents by chelate extraction into an organic solvent, ion-exchange or coprecipitation [8,9], which not only prolong the analysis but can introduce contamination.

The combination of flow injection with atomic absorption spectrometry (FI/ 
AAS) and with atomic emission spectrometry has been shown to be beneficial in terms of extending the performance of atomic spectrometers [10-12]. The benefits of starvation conditions for increasing nebulization efficiency in FI/ AAS have been demonstrated [13-16], and the use of air compensation has been shown to decrease the additional noise produced under such conditions $[15,17]$. On-line precipitation has been used in the indirect determination of anions [18] and for the preconcentration of lead [19]. In this paper, the use of these techniques for the removal of stable compound interferences as exemplified by that of phosphate and aluminium on calcium in the air/acetylene flame is demonstrated.

\section{EXPERIMENTAL}

\section{Equipment and reagents}

Single-line and merging-stream manifolds (Fig. 1) were used. They were constructed from PTFE tubing $(0.58 \mathrm{~mm}$ i.d.). The peristaltic pump was a Gilson Minipuls-2, furnished with PVC pump tubing (2.79 $\mathrm{mm}$ or $1.6 \mathrm{~mm}$ i.d.). The valve arms of a 4 -way rotary valve (Rheodyne 5041 ) were cut to allow injection of volumes of $\leqslant 50 \mu$ l.

The reactor/filter was a minicolumn of glass beads (mesh 35-40), constructed from PVC pump tubing ( $7.5 \mathrm{~cm}$ long, $1.6 \mathrm{~mm}$ i.d.). In the absence of glass beads, the outflow end of the minicolumn was fitted with a filter $(3 \mathrm{~mm}$ Nylon $66 ; 0.45 \mu \mathrm{m}$ pore diameter). The Y-connector for merging streams and $\mathrm{T}$-connector for air compensation were constructed from glass tubing (ca. 0.58 $\mathrm{mm}$ i.d.). The depulser was a T-connector fitted with $6 \mathrm{~cm}$ of pump tubing $(2.79 \mathrm{~mm}$ i.d.) closed at one end. The atomic absorption spectrometer (Baird-

(A)

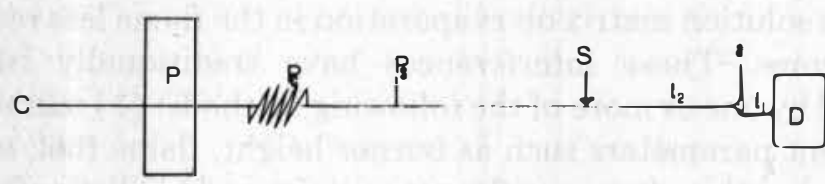

(B)

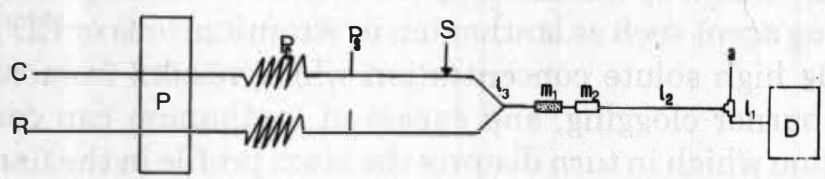

Fig. 1. (A) Single-line manifold; (B) merging-stream manifold. Components: C, carrier; R, reagent stream (ammonia/ammonium oxalate solution); $\mathrm{P}$, pump; $\mathrm{P}_{\mathrm{C}}$, precoil; $\mathrm{P}_{\mathrm{s}}$, pulse suppressor; $\mathrm{S}$, injection point; $\mathrm{D}$, atomic absorption spectrometer; $\mathrm{m}_{1}$, minicolumn of glass beads; $\mathrm{m}_{2}$, guard column to prevent beads blocking nebulizer; a, air compensation inlet; length $l_{1}, 5 \mathrm{~cm}$; length $l_{2}$, $18 \mathrm{~cm}$; length $l_{3}, 26 \mathrm{~cm}$. 
Atomic A3400) was connected to a Philips AR55 chart recorder for absorbance measurements.

Data were collected for magnesium at $285.2 \mathrm{~nm}$ and for calcium at $422.7 \mathrm{~nm}$, with atomization in an air/acetylene flame. A nitrous oxide/acetylene flame was used for the determination of aluminium at $309.3 \mathrm{~nm}$.

Magnesium and calcium solutions were prepared by diluting stock $1000 \mathrm{mg}$ $1^{-1}$ solutions (BDH Spectrosol grade). Orthophosphoric acid (AristaR, 85\% pure) and aluminium chloride (reagent grade, minimum assay $97 \%$ ) were used as interferents. Ammonia/ammonium oxalate and ammonia/ammonium chloride buffer solutions were prepared from BDH AnalaR compounds. Dilute hydrochloric acid (BDH Spectrosol) was used for elution. Reagent-grade water (LiquiPure RG system; reverse osmosis followed by ion-exchange) was used for making up solutions and for the carrier stream.

\section{Procedures}

Effect of FI/AAS parameters. With a single-line manifold, the variation of signal with uptake rate was investigated for a solution of $0.5 \mathrm{mg} \mathrm{l}^{-1}$ magnesium. Nebulization efficiency [13] was also measured. The effect of incorporating a pulse damper into the flow line was investigated.

Phosphate interference. The normal optimization procedures were adopted and calibration was obtained under conditions of maximum sensitivity. The instrument was re-optimized for conditions of minimum interference (10 $\mathrm{mg}$ $\mathrm{l}^{-1}$ calcium in the presence of $200 \mathrm{mg} \mathrm{l}^{-1}$ phosphate ). The effects of dispersion, flow rate, air compensation and operating conditions on the extent of the interference produced for various calcium/phosphate ratios were investigated.

Aluminium interference. The instrumental operating conditions were optimized for minimum interference by $10 \mathrm{mg} \mathrm{l}^{-1}$ aluminium on $10 \mathrm{mg} \mathrm{l}^{-1}$ calcium and the effect of increasing the aluminium concentration was investigated. The use of a single-line manifold with an ammonia carrier stream (to retain the aluminium) and a merging-reagent stream containing ammonium oxalate/ammonia (to retain calcium) was investigated. For the merging-stream manifold, the effects of composition of the reagent, temperature and sample volume were studied. A packed column of glass beads ( $0.5 \mathrm{~mm}$ diameter $)$ and a nylon filter were both used to retain precipitated material. The fate of aluminium in the system was followed by monitoring its atomic absorption in a nitrous oxide/acetylene flame. The same sample loop was used for injection of the hydrochloric acid.

\section{RESULTS AND DISCUSSION}

\section{FI/AAS parameters}

The spectrometer was connected to the single-line manifold shown in Fig. 1A. In the study of flow rate (Fig. 2), the data showed that the steady-state 

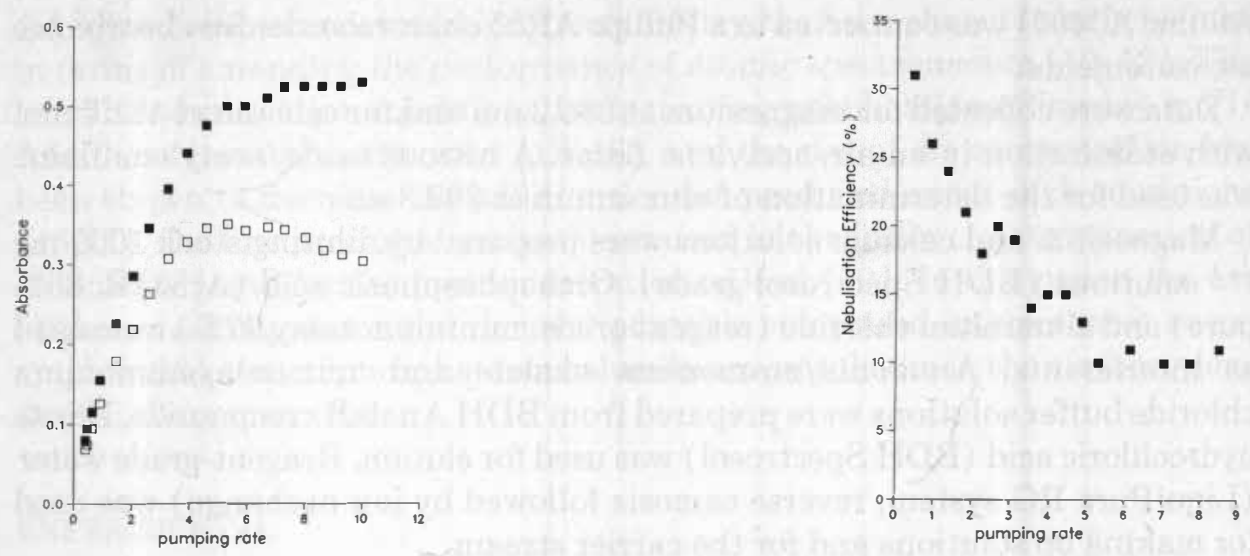

Fig. 2. Effect of pumping rate $\left(\mathrm{ml} \mathrm{min}^{-1}\right)$ on the absorbance for a $0.5 \mathrm{mg} \mathrm{l}^{-1}$ magnesium solution: ( $\square$ ) steady state; $(\square)$ peaks from single-line manifold.

Fig. 3. Effect of pumping rate $\left(\mathrm{ml} \mathrm{min}^{-1}\right)$ on nebulizer efficiency.

absorbance for $0.5 \mathrm{mg} \mathrm{l}^{-1}$ magnesium increased with increased pumping rate to a plateau of about 0.6 , which is the maximum absorbance for that concentration with normal nebulization (suction rate $5-6 \mathrm{ml} \mathrm{min}^{-1}$ ). The "noise" on the steady-state absorbance worsened as the pumping rate decreased, increasing from a relative standard deviation (RSD) of $2 \%$ at $\geqslant 5 \mathrm{ml} \mathrm{min}^{-1}$ to $23 \%$ at $0.4 \mathrm{ml} \mathrm{min}^{-1}$. This noise decreased to about $2 \% \mathrm{RSD}$ when pulse suppressors were incorporated in the manifold. The pulse suppressors also improved the $\mathrm{RSD}$ of the flow-injection peaks to $\leqslant 1 \%$, whilst the air-compensation $\mathrm{T}$-piece minimized the appearance of bubbles and leaks in the manifold by nullifying the nebulizer back-pressure. The variation of nebulization efficiency with uptake rate is shown in Fig. 3.

\section{Phosphate interference on calcium}

When the spectrometer was optimized for maximum sensitivity, absorbance was greatly affected by fuel/oxidant ratio and observation height (Fig. 4). The normal calibration graph was concave towards the concentration axis, and the characteristic concentration was $0.08 \mathrm{mg} \mathrm{l}^{-1}$ in the linear portion $\left(0-2 \mathrm{mg} \mathrm{l}^{-1}\right.$ $\mathrm{Ca}$ ). The flame profile changed so that the absorbance maximum shifted towards a higher fuel flow in the presence of phosphate. There is a fuel-rich region of the flame where the effect of phosphate is minimized (Fig. 4A).

The interference effect of phosphate on calcium under normal aspiration conditions is shown in Fig. 5. There is an enhancement $(\leqslant 4 \%)$ at low phosphate concentrations and a depression $(\leqslant 24 \%)$ at higher phosphate concentrations. Application of flow injection decreased the relative enhancement and depression. The relative interference became less as the dispersion coefficient 

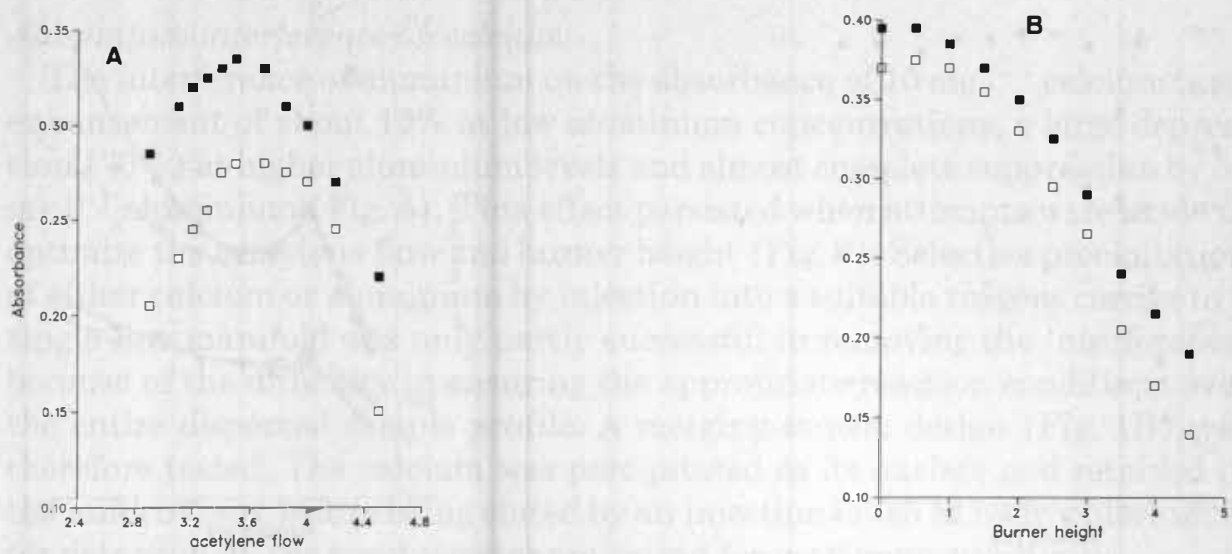

Fig. 4. Effect of acetylene flow rate in $1 \mathrm{~min}^{-1}$ (A) and burner height in $\mathrm{cm}(\mathrm{B}):$ (口) $10 \mathrm{mg} \mathrm{l}^{-1}$ $\mathrm{Ca}$; $\square$ ) $10 \mathrm{mg} \mathrm{l}^{-1} \mathrm{Ca}$ plus $200 \mathrm{mg} \mathrm{l}^{-1}$ phosphate.

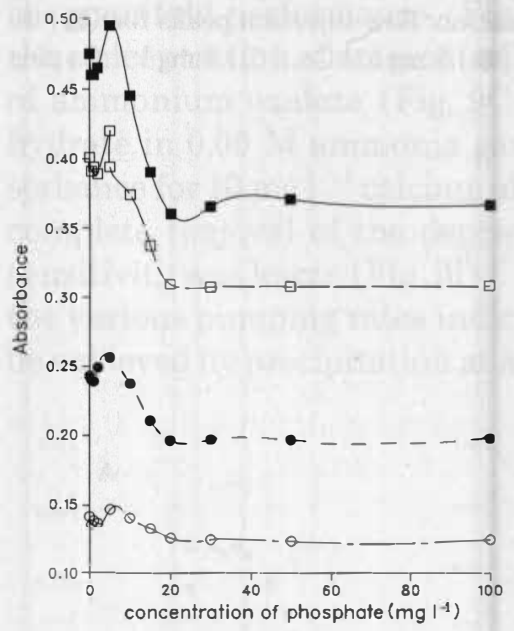

Fig. 5. Effect of phosphate on calcium absorbance with spectrometer optimized for maximum sensitivity: ( $\square$ ) normal nebulization; flow-injection peaks at dispersion coefficients of 1 ( $\square$ ), 2 (O) and 4 (O).

of the manifold increased; thus at a dispersion coefficient of 4 , the enhancement was $1 \%$ and the depression was $10 \%$. The depression was completely removed at low pumping rates $\left(\leqslant 2 \mathrm{ml} \mathrm{min}^{-1}\right.$ ) (Fig. 6) where improved nebulization efficiency aided the removal of the interference. However, a low pumping rate decreased the sensitivity and prolonged the analysis.

A study of the phosphate interference on calcium in the fuel-rich region mentioned earlier showed that the depression was removed for $20-200 \mathrm{mg} \mathrm{l}^{-1}$ phosphate, leaving ca. $10 \%$ enhancement in the $0-20 \mathrm{mg} \mathrm{l}^{-1}$ phosphate range (Fig. 7). The depression was eliminated without sacrificing sensitivity when 

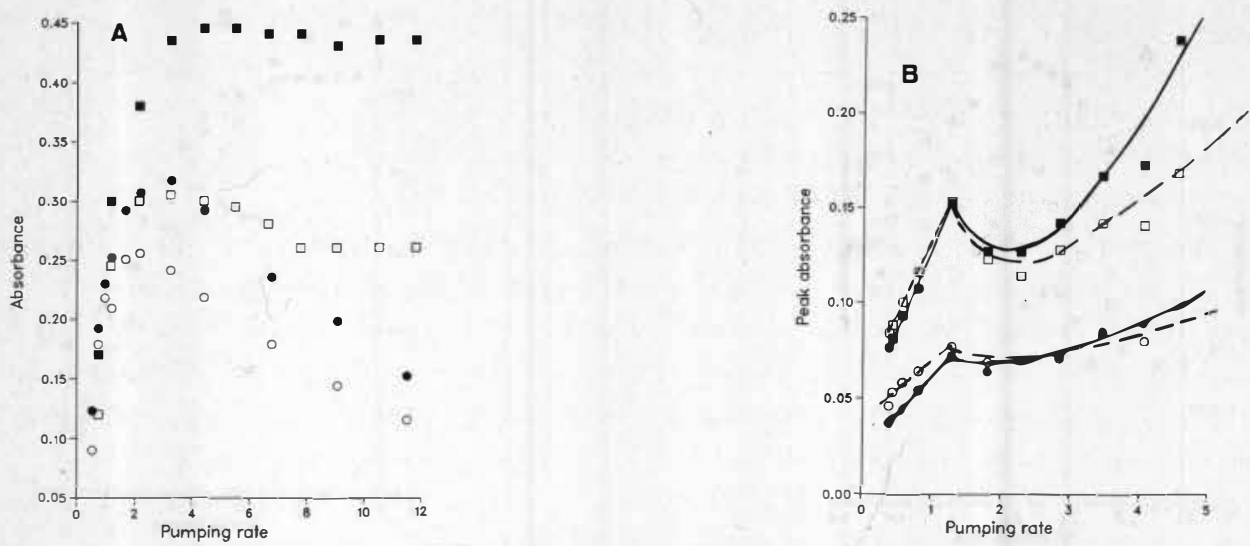

Fig. 6. Effect of pumping rate $\left(\mathrm{ml} \mathrm{min}^{-1}\right)$ on calcium absorbance with spectrometer optimized for maximum sensitivity. (A) without air compensation: steady state for (D) $10 \mathrm{mg} \mathrm{l}^{-1} \mathrm{Ca}$, (ㅁ) $10 \mathrm{mg} \mathrm{l}^{-1}$ plus $200 \mathrm{mg} \mathrm{l}^{-1}$ phosphate; flow-injection peaks for (O) $10 \mathrm{mg} \mathrm{l}^{-1} \mathrm{Ca},(\bigcirc) 10 \mathrm{mg}$ $1^{-1}$ Ca plus $200 \mathrm{mg} \mathrm{t}^{-1}$ phosphate. (B) With air compensation: flow-injection peaks for ( $\square$ ) 10 $\mathrm{mg} \mathrm{l}^{-1} \mathrm{Ca}$, ( $\square$ ) $10 \mathrm{mg} \mathrm{l}^{-1}$ Ca plus $200 \mathrm{mg} \mathrm{l}^{-1}$ phosphate, (O) $5 \mathrm{mg} \mathrm{l}^{-1} \mathrm{Ca}$, (О) $5 \mathrm{mg} \mathrm{l}^{-1}$ Ca plus $200 \mathrm{mg} \mathrm{l}^{-1}$ phosphate.

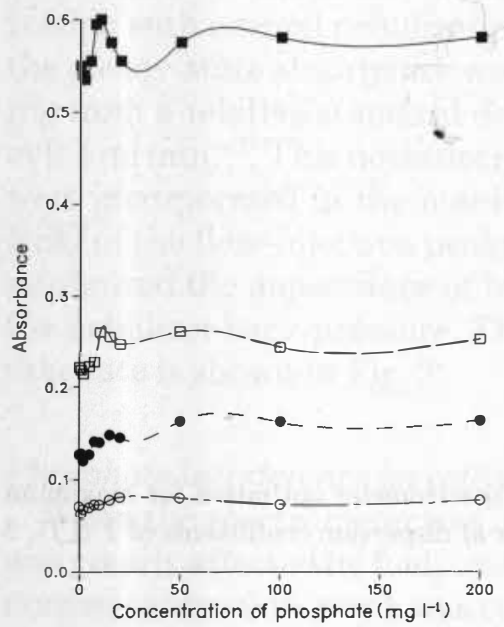

Fig. 7. Effect of phosphate on absorbance of $10 \mathrm{mg} \mathrm{l}^{-1}$ calcium with a fuel-rich flame: $(\square)$ normal nebulization; flow-injection peaks at pumping rates of $2.3(\square), 1.0(\bigcirc)$ and $0.2(O) \mathrm{ml} \mathrm{min}^{-1}$.

the position of the capillary tip in relation to the oxidant inlet in the nebulizer was carefully optimized in addition to the instrument parameters that produced the minimum interference. Application of flow-injection techniques removed the enhancement only at low pumping rates $\left(\leqslant 0.2 \mathrm{ml} \mathrm{min}^{-1}\right)$. 
The interference of aluminium on the absorbance of $10 \mathrm{mg} \mathrm{l}^{-1}$ calcium is an enhancement of about $10 \%$ at low aluminium concentrations, a large depression $(70 \%)$ at higher aluminium levels and almost complete suppression by 50 $\mathrm{mg} \mathrm{l}^{-1}$ aluminium (Fig. 8). This effect persisted when attempts were made to optimize the acetylene flow and burner height (Fig. 8). Selective precipitation of either calcium or aluminium by injection into a suitable reagent carrier in a single-line manifold was only partly successful in removing the interference, because of the difficulty in ensuring the appropriate reaction conditions over the entire dispersed sample profile. A merging-stream design (Fig. 1B) was therefore tested. The calcium was precipitated as its oxalate and retained in the minicolumn, before being eluted by an injection of $0.5 \mathrm{M}$ hydrochloric acid for detection by the spectrometer optimized for maximum sensitivity.

The effects of reagent concentrations and other variables were examined. Changing the temperature from ambient to around $70^{\circ} \mathrm{C}$ had little effect on the manifold performance (Fig. 9A). The precipitation was very sensitive to the concentration of ammonia (Fig. 9B) and required only a low concentration of ammonium oxalate (Fig. 9C). Thus $50 \mathrm{mg} \mathrm{l}^{-1}$ ammonium oxalate monohydrate in $0.05 \mathrm{M}$ ammonia gave a recovery plateau of about $94 \%$ of the absorbance for $10 \mathrm{mg} \mathrm{l}^{-1}$ calcium at a total pumping rate of $1.37 \mathrm{ml} \mathrm{min}^{-1}$. Almost complete removal of the depression was achieved at $2.53 \mathrm{ml} \mathrm{min}^{-1}$ but the sensitivity was lower (Fig. 9D). A close examination of the signals recorded at the various pumping rates indicates that an improvement in sensitivity could be achieved by precipitation at a low pumping rate $\left(\leqslant 1 \mathrm{ml} \mathrm{min}^{-1}\right)$ and elution
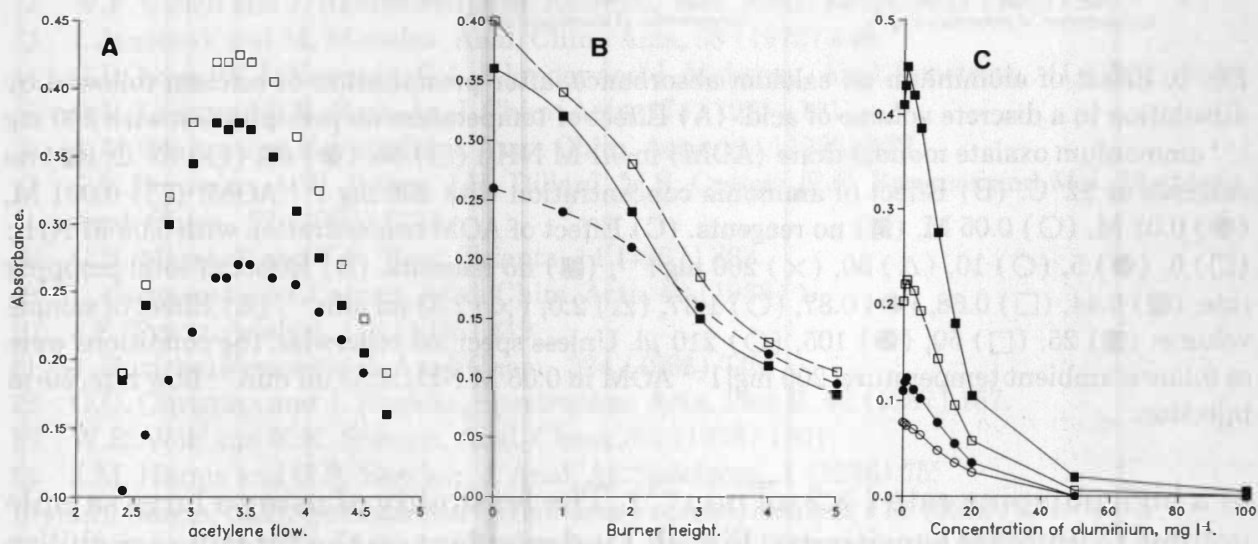

Fig. 8. Effect of acetylene flow rate in $1 \mathrm{~min}^{-1}$ (A) and burner height in $\mathrm{cm}$ (B) on aluminium

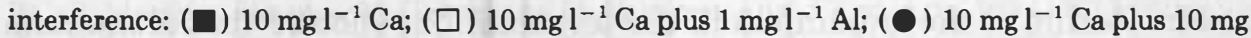
$\mathrm{l}^{-1} \mathrm{Al}$. (C) Effect of aluminium on calcium absorbance with spectrometer optimized for maximum sensitivity: ( $\square$ ) normal nebulization; flow-injection peaks at pumping rates of $3(\square), 1(\bigcirc)$ and 0.2 (O) $\mathrm{ml} \mathrm{min}^{-1}$. 

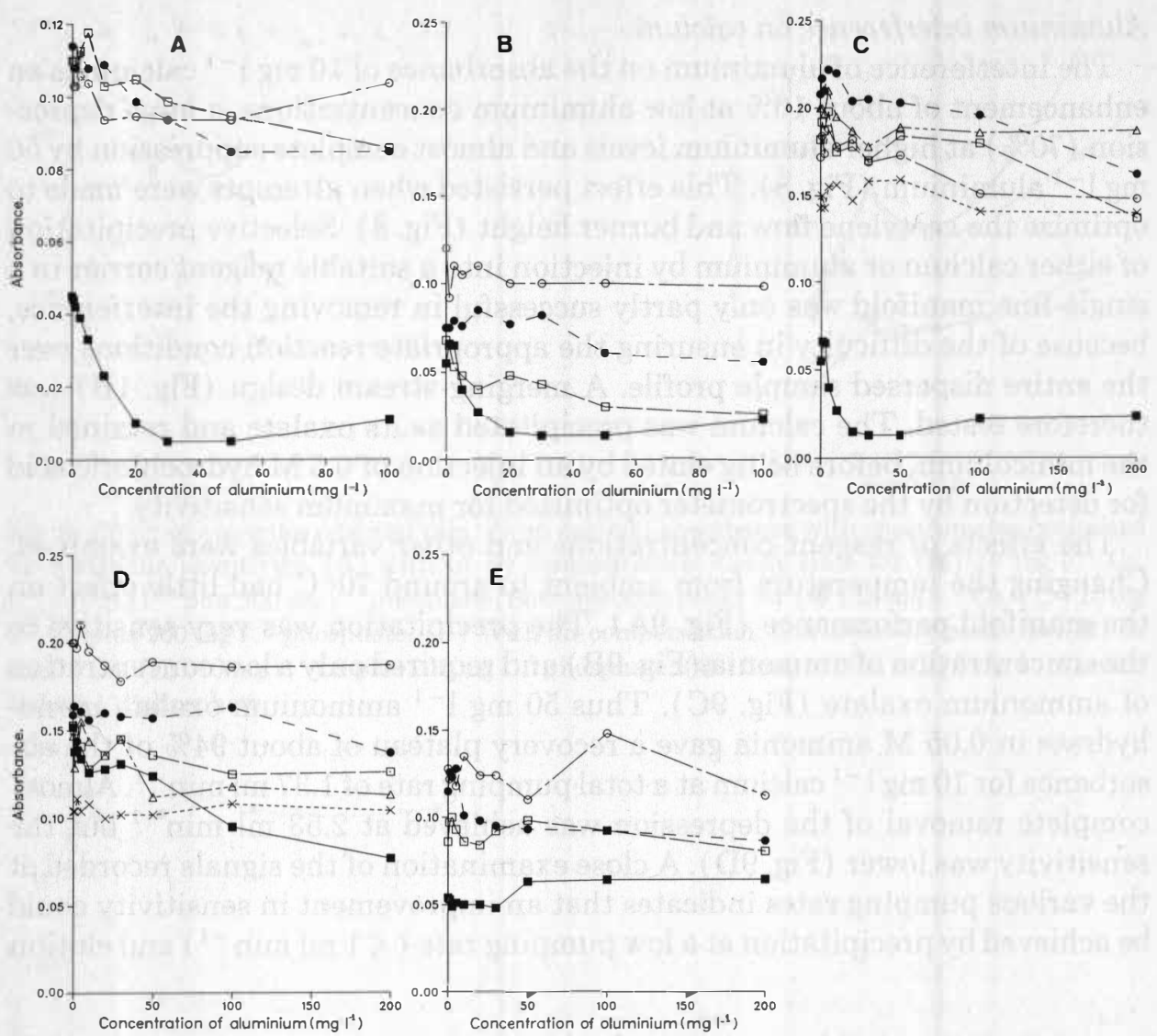

Fig. 9. Effect of aluminium on calcium absorbance, after precipitation of calcium followed by dissolution in a discrete volume of acid. (A) Effect of temperature on precipitation with $200 \mathrm{mg}$ $1^{-1}$ ammonium oxalate monohydrate $(\mathrm{AOM})$ in $0.1 \mathrm{M} \mathrm{NH}_{3}$ : ( $\square$ ) $50,(\bigcirc) 60,(\mathrm{O}) 70^{\circ} \mathrm{C} ;(\mathbf{\square})$ no reagents at $22^{\circ} \mathrm{C}$. (B) Effect of ammonia concentration with $200 \mathrm{mg} \mathrm{l}^{-1} \mathrm{AOM}$ : ( $\square$ ) $0.001 \mathrm{M}$, (O) $0.01 \mathrm{M},(\mathrm{O}) 0.05 \mathrm{M},(\mathbb{\square})$ no reagents. (C) Effect of AOM concentration with $0.05 \mathrm{M} \mathrm{NH}_{3}$ : ( $\square$ ) $0,(\circlearrowleft) 5,(O) 10,(\triangle) 50,(\times) 200 \mathrm{mg} \mathrm{l}^{-1}$; ( $\square$ ) no reagents. (D) Effect of total pumping rate: $(\square) 0.44,(\square) 0.68,(\circlearrowleft) 0.87,(\bigcirc) 1.37,(\triangle) 2.0,(\times) 2.53 \mathrm{ml} \mathrm{min}^{-1}$. (E) Effect of sample volume: $(\square) 25,(\square) 50,(\bigcirc) 105,(O) 210 \mu$ l. Unless specified otherwise, the conditions were as follows: ambient temperature, $200 \mathrm{mgl}^{-1} \mathrm{AOM}$ in $0.05 \mathrm{M} \mathrm{NH}_{3}, 2.53 \mathrm{ml} \mathrm{min}^{-1}$ flow rate, $50-\mu \mathrm{l}$ injection.

at a high pumping rate $\left(\geqslant 2 \mathrm{ml} \mathrm{min}^{-1}\right)$. The feasibility of using a large sample volume to increase sensitivity (Fig. 9E) is dependent on the filtering capability of the minicolumn.

Monitoring of the aluminium in the test solutions showed that aluminium was not retained by the packed beads nor by a string of polyethylene beads or the nylon filter at the outlet of the minicolumn. In such tests, reagents of very high purity with respect to calcium content must be used. Prolonged pumping 
of solutions into the nebulizer eventually produced a noisy baseline. A better design of manifold for further investigations on the interference phenomenon of ions would involve diverting precipitating solutions to waste. Nevertheless, the RSD was $2 \%$ for $10 \mathrm{mg} \mathrm{l}^{-1}$ calcium under the conditions specified.

\section{Conclusion}

Although the depressive effect of phosphate on calcium can be removed by the use of low aspiration rates with consequent improved nebulization efficiencies, a better approach is to adjust the instrument operating parameters. Of these, the position of the nebulizer capillary relative to the oxidant inlet is of critical importance. However, the aluminium interference has to be removed by incorporating a separation procedure. Selective on-line precipitation followed by elution based on flow-injection principles forms the basis of an effective method of separation. The method has many of the advantages of flow-injection procedures such as using a limited sample volume in a contamination-free environment as well as enhanced sensitivity through preconcentration by precipitation of the calcium from a large volume of test solution.

Financial support for C.E.A. from the Commonwealth Scholarship Commission is gratefully acknowledged.

\section{REFERENCES}

1 T.C. Rains, Am. Soc. Test. Mater., Spec. Tech. Publ., 433 (1969) 10.

2 W.F. Ulrich and J. Ramirez-Munõz, Am. Soc. Test. Mater., Proc., 433 (1969) 90.

3 I. Janousek and M. Miroslav, Anal. Chim. Acta, 58 (1972) 448.

4 G.L. Long, W.J. Newman, G.L. Klunder and J. Mahaney, Appl. Spectrosc., 41 (1987) 255.

5 G.L. Long and C.B. Boss, Anal. Chim. Acta, 174 (1985) 191.

6 A.M. Maitra and E. Patsalides, Anal. Chim. Acta, 193 (1987) 179.

7 J.A. Borowiec, A.W. Boorn, J.H. Dillard, M.S. Cresser, R.F. Browner and M.J. Matteson, Anal. Chem., 52 (1980) 1054.

8 G.B. Marshall and T.S. West, Talanta, 14 (1967) 823.

9 L. Szego and J.M. Calvert, Anal. Chim. Acta, 42 (1968) 1.

10 J.F. Tyson, Analyst, 110 (1985) 419.

11 J. Ruzicka, Fresenius' Z. Anal. Chem., 324 (1986) 745.

12 G.D. Christian and J. Ruzicka, Spectrochm. Acta, Part B, 42 (1987) 157.

13 W.R. Wolf and K.K. Stewart, Anal. Chem., 51 (1979) 1201.

14 J.M. Harnly and G.R. Beecher, J. Anal. At. Spectrom., 1 (1986) 75.

15 I.L. Garcia, M.H. Cordoba and C. Sanchez-Pedreno, Analyst, 112 (1987) 271.

16 I.L. Garcia, C. O'Grady and M.S. Cresser, J. Anal. At. Spectrom., 2 (1987) 221.

17 N. Yoza, Y. Aoyagi, S. Ohashi and A. Tateda, Anal. Chim. Acta, 111 (1979) 163.

18 P. Martinez Jimenez, M. Gallego and M. Valcárcel, Anal. Chim. Acta, 193 (1987) 127.

19 P. Martinez-Jimenez, M. Gallego and M. Valcárcel, Analyst, 112 (1987) 1233. 